\title{
Analysis of Fire Blight Shoot Infection Epidemics on Apple
}

\author{
Alan R. Biggs, West Virginia University, Kearneysville Tree Fruit Research and Education Center, Kearneysville; \\ and William W. Turechek and Tim R. Gottwald, United States Department of Agriculture-Agricultural Research \\ Service, Ft. Pierce, FL 34945
}

\begin{abstract}
Biggs, A. R., Turechek, W. W., and Gottwald, T. R. 2008. Analysis of fire blight shoot infection epidemics on apple. Plant Dis. 92:1349-1356.

Fire blight incidence and spread of the shoot blight phase of the disease was studied in four apple cultivars in replicated blocks over 4 years (1994 to 1997). Cv. York was highly susceptible, followed by 'Fuji' and 'Golden Delicious,' which were moderately susceptible, and 'Liberty,' which was least susceptible. On York, the first appearance of shoot blight was within $48 \mathrm{~h}$ of its predicted appearance according to the Maryblyt model in 3 of the 4 years studied. Shoot blight epidemics in York in 1995 and 1996, and Fuji in 1995, were best described with a logistic model that showed apparent infection rates ranging from 0.05 to 0.20 , indicating a low to moderately high rate of disease increase. The spatial positions (row and column) of all infected plants in each subplot were recorded on plot maps on each sampling date. The binomial and $\beta$-binomial distributions were fit to the data to test for spatial aggregation of disease incidence for each cultivar plot. Maximum likelihood estimation was possible for 92 (43.6\%) of the 211 data sets subjected to this analysis. Of these, 35 data sets were better fit by the $\beta$-binomial distribution than the binomial distribution. The binary power law was used to characterize the relationship between the variance among quadrats within each plot to the variance expected for that plot given the observed level of disease incidence. The binary power law provided an excellent fit to the full data set and to nearly all of the subsets and, with $b>1$, indicated that heterogeneity changed systematically with disease incidence. A covariance analysis was conducted to determine the effect of the factors 'year,' 'cultivar,' 'orchard plot,' and 'observation date' on the intercept and slope parameters of the binary power law. In general, plot followed by year had the greatest impact on parameter estimates and is an indication that location and seasonal factors impact heterogeneity of disease, although the specifics could not be ascertained from this study. Ordinary runs analysis was used to analyze the pattern of diseased trees within rows and detected significant nonrandom patterns of disease incidence in $63.5 \%$ of the orchard plots over the 4year study. From these data sets, $68.7 \%$ had significantly fewer runs, particularly at disease incidences greater than 0.1 . The fewer-than-expected runs at incidences greater than 0.10 provides strong evidence of localized spread.
\end{abstract}

Additional keywords: Erwinia amylovora

Fire blight of apple (Malus $\times$ domestica Borkh.) can be found throughout the United States and many other countries and is a serious problem on trees of susceptible apple cultivars (9). Fire blight is caused by the bacterium Erwinia amylovora and occurs also on pear, quince, $R u$ bus spp., and several other rosaceous hosts. The initial inoculum in an established orchard comes from overwintering cankers that remain from prior growing season infections. Bacteria that exude onto canker surfaces are spread by insects to blossoms where infection can occur under appropriate environmental conditions. Secondary inoculum produced from infected blossoms can cause repeated blossom infec-

Corresponding author: A. R. Biggs

E-mail: abiggs2@wvu.edu

Accepted for publication 5 June 2008.

doi:10.1094/PDIS-92-9-1349

(C) 2008 The American Phytopathological Society tions, as well as infections of tender shoots later in the growing season. Primary inoculum for the infection of shoots also can come from shoots that emerge from buds adjacent to overwintering cankers.

Epidemics of the shoot blight phase of fire blight occur sporadically and vary in intensity from year to year depending on the amount of overwintering inoculum, host susceptibility, crop management system, and environmental conditions (23). In the extreme, shoot blight epidemics can be economically devastating on a regional level. Because of the perennial nature of fruit crops, losses occur as a result of direct crop loss in the year in which disease occurs, as well as past and future development costs related to raising trees to the stage of productivity. In recently established apple orchards, total orchard loss can occur under a sequence of favorable conditions that lead to low to moderate levels of primary infection followed by a traumatic event or events (e.g., frost, hail, high wind, and rain) on a regional level that promote widespread inoculum disper- sal and greatly increased host susceptibility due to wounding. The 2000 epidemic in Michigan is a good example in which the southwestern region of the state experienced unusually warm, humid, and wet weather in May (favorable for blossom infection), which was followed by frequent heavy rains and hail during the period of succulent shoot growth. Losses from the 2000 epidemic in Michigan were estimated to be near $\$ 42$ million (Mark Longstroth, personal communication).

Maryblyt is a computerized model for the prediction of fire blight that is widely used by producers, extension advisors, and researchers (16). The program has various modules for the prediction of blossom and shoot blight. Several research articles have been published that provide data to validate the blossom blight component of Maryblyt $(4,6,8,22)$. No one has attempted to validate the shoot blight portion of the model. Prediction of first early shoot blight symptoms in Maryblyt is based on the accumulation of degree days following the first appearance of a source of secondary inoculum, either blossom blight or canker blight, whichever occurs first; however, because wind and insects can disperse the pathogen from other orchards and wild trees, the primary inoculum sources need not necessarily occur within the orchard being monitored. As with blossom blight, dispersal of the pathogen to shoots and foliar surfaces prior to or during an infection event are highly probable (19). Infection of epiphytically or endophytically colonized shoots has been attributed to wounds caused by insects with sucking or piercing mouthparts, and bacterial ooze spread by rain, insects, aerosols, and birds (19). Steiner observed that, following the appearance of first shoot blight symptoms, later shoot infections occur more or less at random (16). However, the pattern of shoot blight development in an orchard has never been studied.

An epidemiological study of the progression of several natural shoot blight epidemics was conducted in replicated blocks of four apple cultivars. The objectives of the study were to validate the shoot blight component of Maryblyt and describe disease progress over the growing season and to determine the temporal and spatial dynamics of apple shoot infection. Such basic knowledge of disease development could provide more specific recommendations for use of bactericides, insecticides, biological controls, or removal of 
diseased shoots by pruning. A report of an earlier analysis of these data was presented previously (2).

\section{MATERIALS AND METHODS}

Orchard planting. The study site, located at the West Virginia University Tree Fruit Research and Education Center, Kearneysville, WV, was a 6-ha orchard established in 1992. The randomized complete block design consisted of six blocks (approximately 0.8 ha/block) and each block consisted of four cultivars: York (Red Yorking), Golden Delicious (Smoothee), Liberty, or Fuji (Red Fuji \#2), all on M. 26 rootstock. Each replicate plot consisted of 135 trees, planted in five rows of 27 trees each, at 2.5 -by-5.5 m spacing, with every 10 th tree a pollinizing cultivar. Pollinizing cultivars included Jonafree, Gala, and Braeburn on M.9 EMLA rootstock. All trees were obtained from Hilltop Nursery (Hartford, MI), except for York, which was obtained from Adams County Nursery (Aspers, PA). Based on visual observation of the trees at planting and several weeks thereafter, it was concluded that Braeburn trees arrived from the nursery with active, overwintering fire blight cankers from infections that occurred in 1991.

Given the lethal nature of the disease, fire blight management was consistent during the entire period of 1992 to 1997 , to minimize the risk of tree loss. Management practices for fire blight included (i) copper applied at the $1-\mathrm{cm}$ stage of leaf development, (ii) one to three applications of streptomycin during the bloom period, as determined with the Maryblyt model (16), and (iii) removal and destruction of infected plant tissues on a weekly basis. Stage of floral bud development was monitored weekly by examining 10 buds on each of the same 10 trees, which were randomly selected in 1993, in each subplot. Air temperature, relative humidity, and leaf wetness were recorded every $20 \mathrm{~s}$ and summarized hourly with a datalogger (model CS21X; Campbell Scientific, Logan, UT) located in a weather shelter positioned in the center of the research orchard (Fig. 1).

Analysis of disease progression. Beginning at approximately 32.2 degree-days (base $=15.6^{\circ} \mathrm{C}$ ) after the first blossom blight infection period, or following the predicted appearance of canker blight symptoms as determined with the Maryblyt model, every tree was inspected visually for the presence of fire blight symptoms. Inspections for blossom blight were conducted by the same individual approximately weekly by a walking survey of the orchard rows for all four cultivars. All shoot blight determinations in 1994 and 1995 were conducted by walking survey; however, given the size of the orchard and the lower incidence of fire blight in 1996 and 1997 on cvs. Fuji, Golden Delicious, and Liberty, the trees were assessed preliminarily by observations from a moving vehicle and then, if disease was observed, follow-up observations were made by walking. Assessments of disease in cv. York were made by walking survey in all years of the study. The locations of trees with at least one infected blossom or shoot were recorded at each observation on plot maps. Following each period of visual inspection, infected tissues were pruned using tools that had not been sterilized or treated with disinfectant and removed from the orchard. Disease incidence was calculated as the percentage of infected trees in each subplot. Disease severity was not determined.

Disease progress was analyzed for each replicate plot (cultivar within blocks) separately. In 1994, data taken on 16 May were used as the starting point for epidemic analysis, with four observation dates included in the analysis. In 1995, data taken on 8 June were used as the stating point for epidemic analysis, with seven observation dates used in the analysis. In 1996, data collected on 3 June were used as the starting point for epidemic analysis, with seven observation dates used in the analysis. In
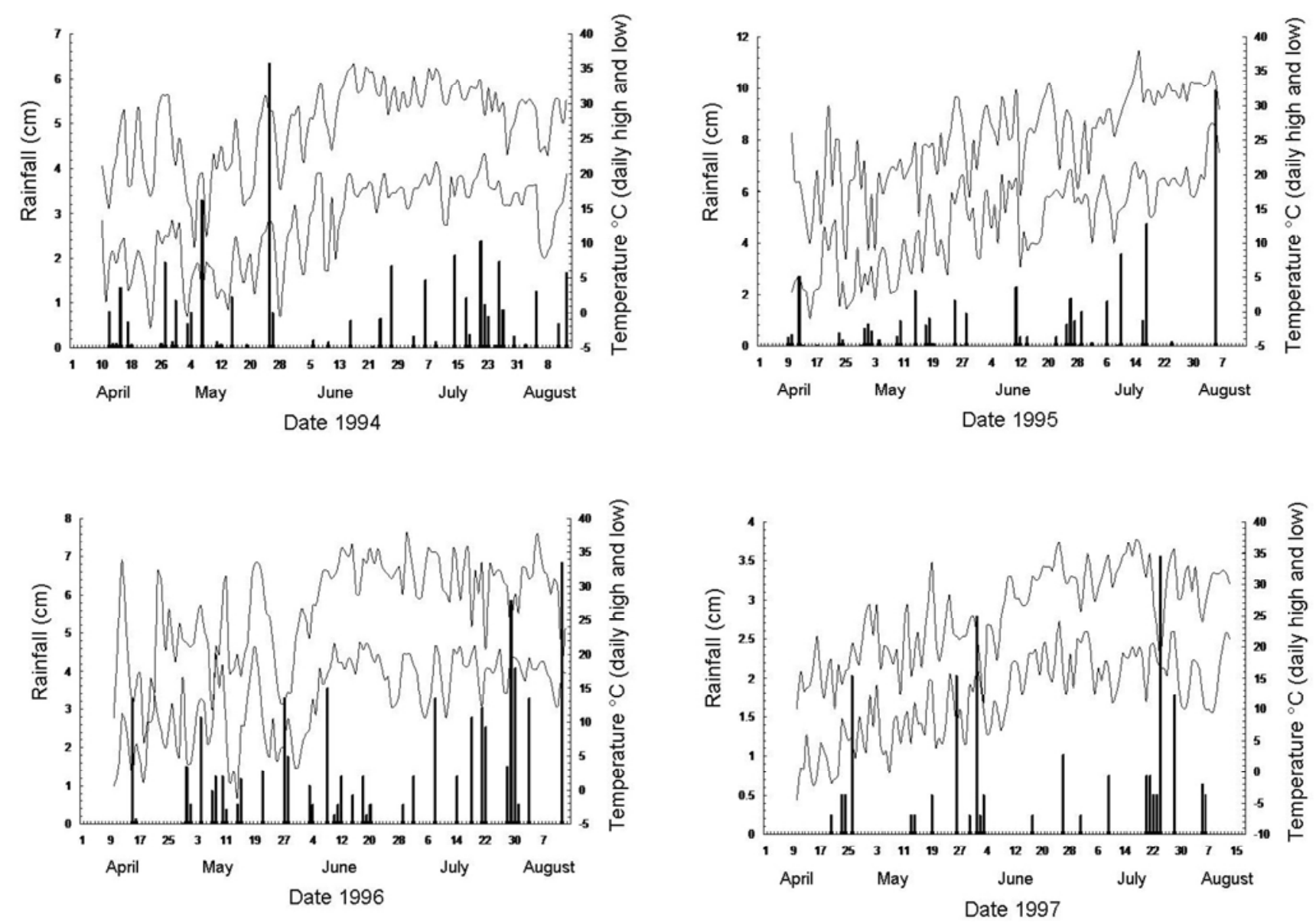

Fig. 1. Daily mean high and low temperature and rainfall for the period April through August 1995-1997. 
1997, data collected on 5 June were used as the starting point for epidemic analysis, with eight observation dates used in the analysis. In the preliminary analyses, disease incidence data were transformed using the linearizing transformation appropriate for the exponential, monomolecular, and logistic models before using ordinary least squares regression to estimate parameters of the linear model. Coefficients of determination $\left(R^{2}\right)$, coefficients of variation, and subjective evaluation of plots of standardized residuals versus predicted values were used to evaluate the appropriateness of a given model. Results of preliminary analyses showed that logistic models fit the data best; therefore, temporal progress was described by transforming mean incidence values $(y)$ to logits and calculating apparent infection rates $(r)$ within plots by regressing $\operatorname{logit}(y)$ against time (days), where $\operatorname{logit}(y)=\ln [y /(1-y)]$. All data were analyzed using the GLM procedure of the Statistical Analysis System (version 9.1; SAS, Cary, NC).

Spatial pattern analysis. The spatial positions (row and column) of all infected plants in each subplot were recorded on plot maps on each sampling date. The binomial and $\beta$-binomial distributions were fit to the data to test for spatial aggregation of disease incidence for each cultivar plot using the program BBD (11). The $\beta$-binomial distribution has two parameters, $p$, which is the expected probability of disease, and $\theta$, which is a measure of the variation in disease incidence among quadrats. A good fit to the binomial distribution is indicative of a random spatial pattern of disease incidence while a good fit to the $\beta$-binomial is indicative of an aggregated pattern of disease incidence. To test the fit of the data to the two distributions, the data were first combined into two-by-two quadrats to produce $N=26$ quadrats of $n=4$ plants for each plot at each observation date. Because there was an odd number of trees within each row and the number of rows within each plot was odd, the last tree in each row and the last row in each plot were omitted during the quadratization. A log-likelihood ratio test statistic (LRS) was calculated for each data set per orchard plot to test the hypotheses that the $\beta$-binomial fitted the data better than the binomial (24).

The binary power law was used to characterize the relationship between the vari- ance among quadrats within each plot to the variance expected for that plot given the observed level of disease incidence. The binary power law can be written as:

$\ln \left(v_{\text {obs }}\right)=\ln \left(A_{\mathrm{x}}\right)+b \ln [n p(1-p)]$

where $n p(1-p)$ is the binomial variance, and $\ln \left(A_{\mathrm{x}}\right)$ and $b$ are the intercept and slope of a straight line (21). When $A_{\mathrm{x}}$ and $b$ are equal to 1 , the disease incidence is randomly distributed. When $b=1$ and $A_{\mathrm{x}}>1$, the data are aggregated but the degree of heterogeneity is independent of $p$. When $b$ and $A_{\mathrm{x}}$ are greater than 1 , the degree of heterogeneity changes with $p$. The power law was run on the full set of data and then on subsets of the data partitioned by the factors year, cultivar, and plot.

A covariance analysis was conducted to determine the effect of the factors 'year' (1994, 1995, 1996, and 1997), 'cultivar' (Fuji, Golden Delicious, Liberty, and York), 'orchard plot' (1 to 6), and 'observation date' ( 1 to 7 or 8 ) on the intercept and slope parameters of the binary power law. Separate covariance analyses were conducted on the 1995 subset of the data (the only year with appreciable fire blight) to determine the effects of cultivar, orchard plot, and observation date on the power law parameters, and on the York subset of the data (the only cultivar with appreciable fire blight) to determine the effects of year, orchard plot, and observation date on the power law parameters. To perform the analysis, factors were added individually to the power law model (null model), first as an intercept term and then as an interaction term with the slope. A factor was considered significant if its inclusion as a covariate significantly reduced the sum of square error (SSE) relative to the null model. The significance level for the difference between SSE of the models was determined with an $F$ test where $F=$ (factor SSE/df factor)/(model SSE/df model), and $\mathrm{df}=$ degrees of freedom.

Ordinary runs analysis was used to analyze the pattern of diseased trees within rows. A run is a sequence of trees with the same disease status $(7,20)$. To perform the analysis, diseased trees were assigned a ' 1 ' and healthy trees were assigned a ' 0 ', the rows were combined in a serpentine pattern such that total number of trees for the analysis was 135 , and then the total number of runs was calculated. For example, the sequence 1-1-0-1-0-0 contains four runs (i.e., 1-1, 0, 1, and 0-0). The total number of runs was compared with the expected number of runs to calculate a standard normal $z$ statistic and test the null hypothesis of a random distribution of infected trees. Runs analysis is the only test for randomness based on the order of the sequence (7).

\section{RESULTS}

Blossom infection periods occurred in 2 of the 4 years of the study, according to the Maryblyt model (Table 1) and confirmed by observations. First blossom blight symptoms were observed within 1 day of the predicted date. In 1995 and 1997, years in which blossom blight was neither predicted nor observed, spread of bacteria from overwintering cankers was presumed to be the sole source of primary inoculum for the subsequent shoot blight epidemic. The first observed appearance of shoot blight symptoms occurred within $48 \mathrm{~h}$ of the Maryblyt prediction in 3 of the 4 years (Table 1).

Of the 4 years studied, disease incidence was highest on all cultivars in 1995. Disease incidence was consistently highest on York in all 4 years of the study. By the end of the measurement period in each season (early August), disease incidence in the six subplots of York ranged from $\hat{p}=0.02$ to 0.16 in 1994 , from 0.21 to 0.88 in 1995 , from 0.01 to 0.38 in 1996, and from 0 to 0.10 in 1997 (the incidence values for 1995 in Table 2 are slightly different than indicated here due to truncation of the rows and columns that resulted from quadratizing the data). For the other cultivars, $\hat{p} \leq 0.03$, except in 1995, when maximum disease incidence for cvs. Fuji, Liberty, and Golden Delicious was $\hat{p}=0.31,0.31$, and 0.08 , respectively.

Analysis of disease progress. Fire blight was first detected at the research site in 1992 when visibly diseased plants (dead shoots with shepherd's crook symptom and cankers on main stem) were received from the nursery and observed at the time of planting. No blossom blight or shoot blight was observed in 1992 or 1993; however, in 1994 following conditions favorable for blossom infection, approximately $16 \%$ of York trees exhibited shoot blight by the end of the growing season. Conditions for disease development were very favorable in 1995 and these data were the most useful for analy-

Table 1. Predicted blossom blight infection periods, and predicted and observed dates of blossom blight, canker blight, and shoot blight symptoms ${ }^{\mathrm{a}}$

\begin{tabular}{|c|c|c|c|c|c|c|c|}
\hline Year & $\begin{array}{l}\text { Predicted first } \\
\text { blossom blight } \\
\text { infection period }\end{array}$ & $\begin{array}{l}\text { Predicted first } \\
\text { blossom blight } \\
\text { symptoms }\end{array}$ & $\begin{array}{c}\text { First blossom } \\
\text { blight symptoms } \\
\text { observed }\end{array}$ & $\begin{array}{l}\text { Predicted canker } \\
\text { blight symptoms }\end{array}$ & $\begin{array}{l}\text { Observed canker } \\
\text { blight symptoms }\end{array}$ & $\begin{array}{l}\text { Predicted shoot } \\
\text { blight symptoms }\end{array}$ & $\begin{array}{l}\text { Observed shoot } \\
\text { blight symptoms }\end{array}$ \\
\hline 1994 & 26 April 1994 & 15 May 1994 & 15 May 1994 & 26 May 1994 & None & 30 May 1994 & 31 May 1994 \\
\hline 1995 & None & NA & None & 28 May 1995 & 30 May 1995 & 6 June 1995 & 8 June 1995 \\
\hline 1996 & 3 May 1996 & 17 May 1996 & 17 May 1996 & 18 May 1996 & None & 23 May 1996 & 29 May 1996 \\
\hline 1997 & None & NA & None & 24 May 1997 & 30 May 1997 & 6 June 1997 & 5 June 1997 \\
\hline
\end{tabular}

a Predictions based on Maryblyt version 4.3c. "None" indicates that no infections were predicted or no symptoms were observed. NA indicates that there were no predicted first symptoms because there was no predicted first blossom blight infection period. 
sis of disease progress. York exhibited the highest incidence of disease in all years, and data from this cultivar for 1995 are presented (Fig. 2). The plot of disease incidence $(y)$ versus time $(t)$ for these epidemics indicated that logistic transformations best described disease progress over time $(11,13)$. Disease increase in York in 1995 was characterized by apparent infection rates ranging from 0.053 to 0.20 /day (Fig. 2). Fuji in 1995 showed an apparent infection rate of 0.16/day, and York in 1996 exhibited an apparent infection rate of $0.076 /$ day (Fig. 2).

Spatial pattern analyses. Maximum likelihood estimation was possible for 92 $(43.6 \%)$ of the 211 data sets subjected to BBD analysis (Table 3). With the exception of Fuji, most of the data sets where the procedure was not able to converge (i.e., fit the $\beta$-binomial distribution) had incidences of shoot blight $<0.10$. Of the 92 data sets where maximum likelihood estimation was possible, only 35 data sets fit better to the $\beta$-binomial distribution compared with the binomial distribution. For the 92 data sets, estimates of the heterogeneity parameter of the $\beta$-binomial distribution $(\hat{\theta})$ ranged from 0.007 to 0.855 . The median value varied considerably among cultivars and disease incidence class. Median values of $\hat{\theta}$ were less than 0.059 when disease incidence was less than $P=0.1$, indicating a low degree of aggregation. With the exception of Fuji, $\hat{\theta}$ increased with incidence and achieved its maximum median value in the incidence class 0.4 to 0.6 ; this is expected for data that follow a $\beta$-binomial distribution. Identical trends were found with the index of dispersion, $D$.

The binary power law provided an excellent fit to the full data set and to nearly all of the subsets (Table 2). The estimated intercept and slope parameters were significantly different from 0 and 1 according to a $t$ test for all data sets, with the excep- tion of the 1997 data subset, the Liberty data subset, and the plot 3 data subset, where only the intercept parameter was significantly different from 0 . The analysis by subsets is intended to provide insight into how the power law parameters for the full data set vary among the possible covariates (discussed in further detail below). In general, the excellent fit to the data and the fact that $b>1$ indicates that heterogeneity (i.e., $\hat{\theta}$ ) changed systematically with disease incidence.

The covariance analysis for the full data set indicated that year had a significant impact on the slope parameter and that cultivar and plot had a significant impact on the intercept parameter of the power law. For the 1995 subset, the covariance analysis indicated that cultivar had a significant effect on the intercept parameter and that plot had a significant effect on both the intercept and slope parameters. For the York subset, year and plot had significant effects on both model parameters (Table 4). Ordinary runs analyses were able to detect significant $(P<0.05)$ nonrandom patterns of disease incidence in $64 \%$ of the orchard plots over the 4year study (Table 3). A significantly greater number of runs were found in $31 \%$ of the data sets; these occurred exclusively in the lowest incidence class for all cultivars except Golden Delicious (Table 3). Significantly fewer runs were found in $69 \%$ of the data sets, indicating aggregation at higher incidences (Table 3 ). There was a clear departure of the observed $z$ statistic from its expected value for disease incidence values between 0.1 and 0.7 (Fig. 3).

\section{DISCUSSION}

Maryblyt predicted the onset of shoot blight symptoms within $48 \mathrm{~h}$ of their appearance in 3 of the 4 years studied (1994, 1995, and 1997), and this report is the first to validate the shoot blight portion of the
Maryblyt model. The basis for shoot blight predictions in the Maryblyt model is the presence of blossom blight or canker blight plus 375 accumulated degree-days (base $4.4^{\circ} \mathrm{C}$ ) after bud break (i.e., green tip). The required degree-day accumulation is based on the appearance of adults of the putative vector, white apple leaf hopper (16).

The insects that are most important in contributing to epidemics of shoot blight vary by site and region. In the mid-Atlantic region and many other parts of the United States, early shoot blight symptoms are most closely associated with the activity of winged adults of the white apple leafhopper. These first appear after 375 degreedays $>4.4^{\circ} \mathrm{C}$ after green tip, and Maryblyt uses this as the predictor for first shoot blight (375 degree-days $>4.4^{\circ} \mathrm{C}$ for insect development +57 degree-days $>12.7^{\circ} \mathrm{C}$ for symptom development following infection). Wetting events are thought to be not necessary for shoot blight infection and; therefore, are not included in this part of the model. The role of green apple aphid has been minimized by studies by Clark et al. (5). An important role for potato leafhoppers has been proposed by Pfeiffer et al. (15). The feeding habits of potato leafhopper seem particularly suited to creating wounds in tender tissues that could become infected if inoculum was present and environmental conditions were suitable. Alternatively, it has been proposed that wind is a suitable wounding agent (3). Wind and inoculum present in wind-driven rain could initiate a shoot blight epidemic in the absence of insect injuries. No variations in insect occurrence or development rate were noted (unpublished data); therefore, the delay in shoot blight appearance in 1996 could not be explained by differences in vector populations or their rate of development. Additional research is needed to gain a better understanding of the role of insects and weather in the development of shoot blight epidemics and to

Table 2. Estimated parameters of the binary power law (equation 1) and their standard errors (se) for the incidence of shoot blight in experimental orchard plots in Kearneysville, WV from 1994 to $1997^{\mathrm{a}}$

\begin{tabular}{|c|c|c|c|c|c|c|c|c|}
\hline Data set & $N$ & $R^{2}$ & $\ln \left(A_{x}\right)$ & se $\ln \left(A_{x}\right)$ & $t$ & $b$ & se $b$ & $t$ \\
\hline $\begin{array}{l}\text { Full data set } \\
\text { Year }\end{array}$ & 211 & 0.96 & 0.333 & 0.034 & 9.79 & 1.097 & 0.016 & 6.06 \\
\hline 1994 & 11 & 0.99 & 0.162 & 0.075 & 2.16 & 1.066 & 0.033 & 2.00 \\
\hline 1995 & 123 & 0.96 & 0.398 & 0.040 & 9.95 & 1.116 & 0.020 & 5.80 \\
\hline 1996 & 41 & 0.98 & 0.259 & 0.051 & 5.08 & 1.077 & 0.024 & 3.21 \\
\hline 1997 & 34 & 0.84 & -0.277 & 0.168 & -1.65 & 0.868 & 0.065 & -2.03 \\
\hline \multicolumn{9}{|l|}{ Cultivar } \\
\hline Fuji & 34 & 0.97 & 0.184 & 0.077 & 2.39 & 1.039 & 0.033 & 1.18 \\
\hline Golden & 24 & 0.99 & 0.191 & 0.051 & 3.75 & 1.075 & 0.021 & 3.57 \\
\hline Liberty & 28 & 0.94 & 0.406 & 0.114 & 3.56 & 1.080 & 0.054 & 1.48 \\
\hline York & 125 & 0.96 & 0.366 & 0.043 & 8.51 & 1.113 & 0.021 & 5.38 \\
\hline \multicolumn{9}{|l|}{ Plot } \\
\hline 1 & 36 & 0.92 & 0.464 & 0.109 & 4.26 & 1.115 & 0.055 & 2.09 \\
\hline 2 & 36 & 0.99 & 0.382 & 0.050 & 7.64 & 1.110 & 0.022 & 5.00 \\
\hline 3 & 39 & 0.94 & 0.125 & 0.065 & 1.92 & 1.064 & 0.044 & 1.45 \\
\hline 4 & 26 & 0.97 & 0.727 & 0.122 & 5.96 & 1.187 & 0.045 & 4.16 \\
\hline 5 & 36 & 0.98 & 0.365 & 0.060 & 6.08 & 1.117 & 0.025 & 4.68 \\
\hline 6 & 38 & 0.97 & 0.459 & 0.069 & 6.65 & 1.194 & 0.033 & 5.88 \\
\hline
\end{tabular}

${ }^{\mathrm{a}} \ln \left(A_{\mathrm{x}}\right)$ and $b$ are the intercept and slope estimates, respectively, of the binary power law (eq. 1). 
ascertain the biological basis for the shoot blight symptom portion of Maryblyt. Our observations of blossom blight development in relation to Maryblyt predictions were in agreement with previous studies $(4,6,8,22)$.

Of the four cultivars examined, disease incidence and rate of disease increase was greatest in York. This observation agrees with previous reports of high susceptibility of cv. York to E. amylovora $(1,17,18)$. However, Fuji has been reported to be as highly susceptible as York (18), and our results do not support this ranking. Differences in genetic strains within particular apple cultivars, as well as edaphic and phenological conditions that affect disease development, may explain the differences in susceptibility among the various reports.

The mathematical description of these fire blight epidemics by the logistic model has been associated with a polycyclic disease cycle, which is typified by the secon- dary spread of inoculum $(10,12)$. For cv. York, the apparent infection rate for shoot blight ranged from 0.053 to 0.20 /day in 1995, the year in which shoot blight was most severe. These values show that disease incidence can increase dramatically, easily doubling in 3 to 5 days when environmental conditions and host susceptibility are highly favorable. It should be noted that these infection rates were observed under a disease management strategy that was considered optimal at the time (i.e.,
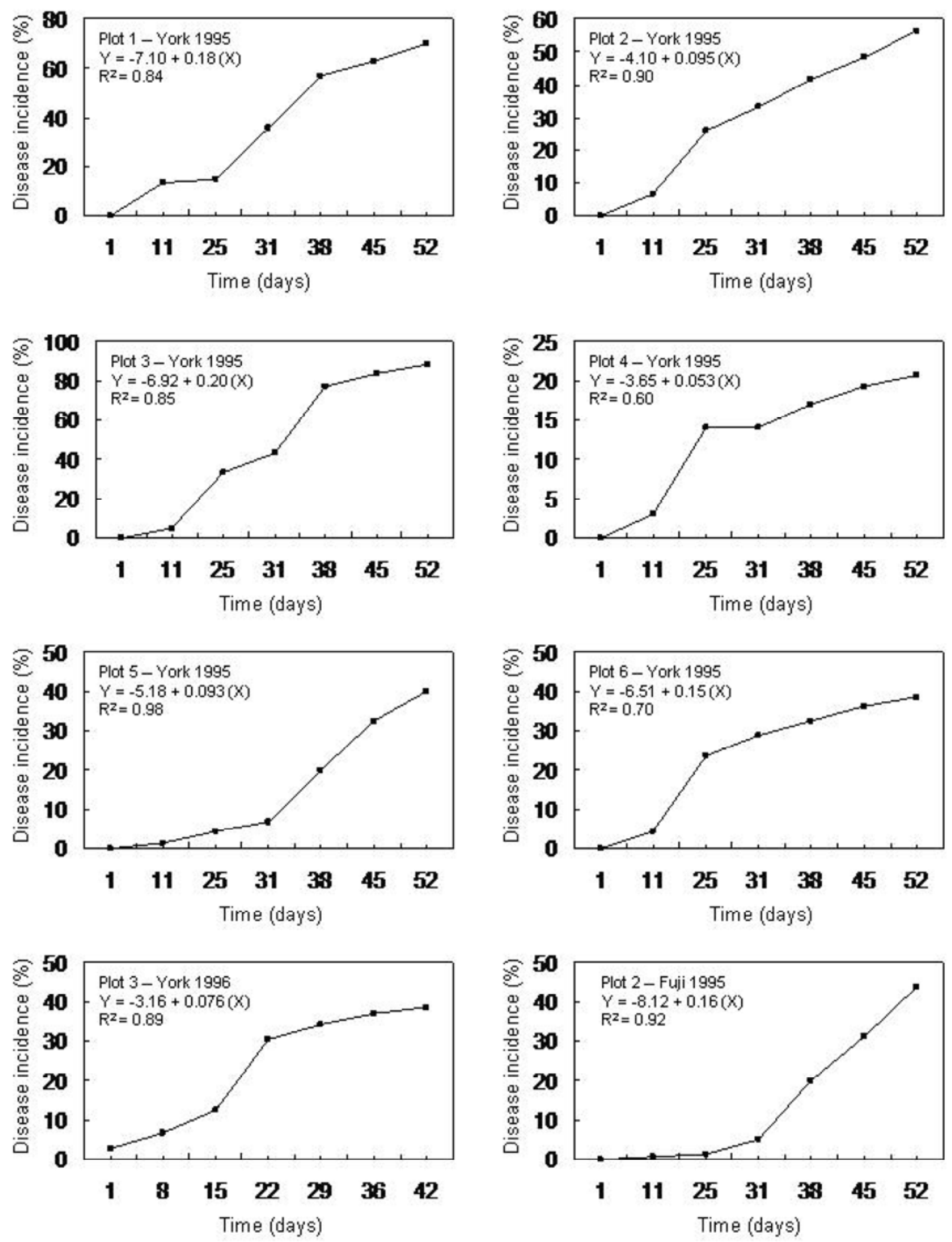

Fig. 2. Disease progress of fire blight shoot blight incidence on York apple in six plot locations in 1995, one plot location in 1996, and on Fuji apple in one plot location in 1995. In 1995, day 1 of the epidemic is 8 June. In 1996, day 1 of the epidemic is 3 June. The equations describe the logit of fire blight shoot incidence versus time. The slopes of the regression lines are the apparent rate of shoot blight spread (logit/day). 
copper applied at the 1-cm stage of leaf development, applications of streptomycin during the bloom period as determined with the Maryblyt model [16], and removal and destruction of infected plant tissues on a weekly basis). The plant growth regulator Apogee (prohexadione-calcium; BASF Corporation) is a new horticultural tool that was not available for use at the time of these observations. Apogee acts to reduce the rate shoot internode elongation, resulting in decreased susceptibility of shoots to E. amylovora infection (26). Its use at the proper application rate and timing may have resulted in significantly less shoot blight. Indeed, in Virginia, field trials have shown reductions in shoot blight assessed in June and July of 88 to $96 \%$ (25). The current recommended timing for Apogee is to make the first application at the petal fall stage of the king blooms, with additional sprays applied as needed (14).
Both the distributional analyses and ordinary runs analysis indicated aggregation of shoot blight within orchard plots. The degree of aggregation was generally low at incidence values $<0.05$ and $>0.80$, and was greatest at levels of incidence within the range of 0.20 to 0.60 . This is typical of a disease that can be described by the $\beta$ binomial distribution. Recall that aggregation here describes clustering within sampling units of $n=4$ trees, and that this type of analysis is based on the frequency distribution of sampling units with $0,1,2,3$, or 4 diseased trees in a plot and does not consider the spatial position of sampling units within plots. In contrast, ordinary runs analysis does consider the spatial positioning of trees to test the null hypothesis of a random arrangement of diseased trees and complements the results of the distribution analysis. The fewer than expected runs at incidences greater than 0.10 provide strong evidence of localized spread and support the results of the distribution analysis. Localized and directional spread of fire blight also has been observed in simulated apple nursery plantings (13). Whether this localized spread is due primarily to rubbing branches, insects, blowing rain, or any combination of the three cannot be deduced from the analysis.

The binary power law and covariance analyses indicated that differences in spatial heterogeneity can be attributed largely to yearly effects and block (plot) (i.e., the six groups of four cultivars). Yearly differences in heterogeneity were not unexpected and have been observed in other perennial systems that have been scouted over several years (21). This is particularly true in systems where the severity of epidemics is highly variable from year to year. In the orchard plots of this study, there was no clear trend in how aggregation changed among years (Table 4); how-

Table 3. Summary of distributional and ordinary runs analyses characterizing the spatial pattern of disease incidence of shoot blight in experimental orchard plots in Kearneysville, WV from 1994 to 1997

\begin{tabular}{|c|c|c|c|c|c|c|c|c|c|}
\hline \multirow[b]{2}{*}{ Cultivar, incidence class ${ }^{b}$} & \multirow[b]{2}{*}{$N^{\mathrm{c}}$} & \multirow[b]{2}{*}{ MLE $^{d}$} & \multirow[b]{2}{*}{$\mathbf{L R S}^{\mathbf{e}}$} & \multicolumn{3}{|c|}{ Median values } & \multicolumn{3}{|c|}{ Ordinary runs ${ }^{\mathrm{a}}$} \\
\hline & & & & $p^{\mathbf{f}}$ & $D^{\mathrm{g}}$ & $\hat{\theta}^{\mathbf{h}}$ & $z$ & - & + \\
\hline \multicolumn{10}{|l|}{ Fuji } \\
\hline $0.00-0.05$ & 19 & 21.1 & 5.26 & 0.010 & 1.01 & 0.000 & 4.26 & 3 & 13 \\
\hline $0.05-0.10$ & 5 & 80.0 & 0.00 & 0.077 & 1.06 & 0.007 & -1.22 & 1 & 0 \\
\hline $0.10-0.20$ & 1 & 100 & 100 & 0.164 & 2.48 & 0.855 & -6.28 & 1 & 0 \\
\hline $0.20-0.40$ & 4 & 50.0 & 25.0 & 0.289 & 0.98 & 0.004 & -2.92 & 4 & 0 \\
\hline $0.40-0.60$ & 2 & 0 & 0 & 0.452 & 0.85 & 0.000 & -2.65 & 1 & 0 \\
\hline $0.60-0.80$ & 1 & 100 & 0 & 0.750 & 1.28 & 0.083 & -2.51 & 1 & 0 \\
\hline $0.80-1.00$ & 2 & 0 & 0 & 0.837 & 1.01 & 0.000 & -0.78 & 0 & 0 \\
\hline All & $34(8)$ & 35.3 & 8.8 & 0.043 & 1.01 & 0.000 & -0.43 & 11 & 13 \\
\hline \multicolumn{10}{|l|}{ Golden Delicious } \\
\hline $0.00-0.05$ & 19 & 0 & 0 & 0.019 & 0.98 & 0.000 & -1.30 & 8 & 0 \\
\hline $0.05-0.10$ & 4 & 100 & 0 & 0.087 & 1.21 & 0.059 & -1.44 & 1 & 0 \\
\hline $0.10-0.20$ & 1 & 100 & 0 & 0.135 & 1.24 & 0.069 & -0.96 & 0 & 0 \\
\hline $0.20-1.00$ & $\ldots$ & $\ldots$ & $\ldots$ & $\ldots$ & $\ldots$ & $\ldots$ & $\ldots$ & $\ldots$ & $\ldots$ \\
\hline All & $24(18)$ & 20.8 & 0 & 0.024 & 0.98 & 0 & -1.30 & 9 & 1 \\
\hline \multicolumn{10}{|l|}{ Liberty } \\
\hline $0.00-0.05$ & 15 & 40.0 & 26.7 & 0.019 & 1.01 & 0.000 & 1.18 & 5 & 2 \\
\hline $0.05-0.10$ & 8 & 87.5 & 87.5 & 0.077 & 1.18 & 0.045 & -0.66 & 2 & 0 \\
\hline $0.10-0.20$ & 1 & 100 & 0 & 0.125 & 1.51 & 0.177 & -3.93 & 1 & 0 \\
\hline $0.20-0.40$ & 3 & 100 & 66.7 & 0.250 & 1.60 & 0.219 & -3.66 & 3 & 0 \\
\hline $0.40-0.60$ & 1 & 100 & 100 & 0.442 & 1.65 & 0.241 & -4.59 & 1 & 0 \\
\hline $0.60-1.00$ & t & $\ldots$ & & $\ldots$ & & $\ldots$ & $\ldots$ & $\ldots$ & $\ldots$ \\
\hline All & $28(14)$ & 64.3 & 25.0 & 0.039 & 1.23 & 0.060 & -1.37 & 12 & 2 \\
\hline \multicolumn{10}{|l|}{ York } \\
\hline $0.00-0.05$ & 62 & 14.5 & 9.68 & 0.014 & 1.01 & 0.000 & 1.37 & 19 & 26 \\
\hline $0.05-0.10$ & 19 & 52.6 & 5.26 & 0.053 & 1.06 & 0.007 & -0.50 & 5 & 0 \\
\hline $0.10-0.20$ & 18 & 88.9 & 33.3 & 0.125 & 1.41 & 0.136 & -3.62 & 13 & 0 \\
\hline $0.20-0.40$ & 14 & 92.9 & 42.9 & 0.341 & 1.50 & 0.174 & -3.76 & 13 & 0 \\
\hline $0.40-0.60 *$ & 7 & 85.7 & 57.1 & 0.442 & 1.95 & 0.413 & -4.38 & 7 & 0 \\
\hline $0.60-0.80^{*}$ & 3 & 100 & 66.7 & 0.664 & 1.70 & 0.267 & -4.42 & 3 & 0 \\
\hline $0.80-1.00 *$ & 2 & 0 & 0 & 0.837 & 1.01 & 0.000 & -0.78 & 0 & 0 \\
\hline All & $125(43)$ & 45.6 & 20.0 & 0.058 & 1.01 & 0.000 & -1.63 & 60 & 26 \\
\hline All & $211(83)$ & 43.6 & 16.6 & 0.039 & 1.01 & 0.000 & -1.30 & 92 & 42 \\
\hline
\end{tabular}

${ }^{a}$ Median value of ordinary runs $z$-statistic and the number of data sets that showed significantly fewer (-) or greater (+) number of runs out of $N$ than expected in that incidence class.

${ }^{\mathrm{b}}$ Classes end with the listed incidence value and begin with the first value above the listed value in each class. The number in parentheses is the number of observations where shoot blight was not observed. Except for York, data represent incidence values observed in 1995 only; very low incidence of shoot blight was observed in the other years of the study. For the cultivar York, the data summarize all 4 years of the study. However, incidence classes identified by '*' are observations from 1995 only; disease incidence did not exceed 0.4 in the other years of the study.

${ }^{c}$ Number of data sets in defined incidence class.

${ }^{\mathrm{d}}$ Percent of data sets where the maximum likelihood estimation (MLE) procedure converged to provide estimates of the $\beta$-binomial parameters $p$ and $\theta$.

${ }^{\text {e }}$ Percent of data sets where the $\beta$-binomial distribution fit the data better than the binomial distribution according to the likelihood ratio test.

${ }^{\mathrm{f}}$ Median disease incidence.

$\mathrm{g}$ Median index of dispersion.

${ }^{\mathrm{h}}$ Median estimated $\beta$-binomial dispersion parameter. 
ever, one can speculate that these differences may be due in part to annual variation in seasonal climate patterns (1995 being a particularly favorable year), changes in crop physiology, or changes in the pathogen population. The fact that block had such a strong effect on heterogeneity is an indication that local factors have a large impact on epidemic development. Similar to the effects observed for year, however, it is not clear from the analyses what factors are responsible for the observed change in aggregation. Some possibilities include how initial inoculum is distributed within plots and whether secondary inoculum is distributed by insects or wind-driven water. From a mathematical perspective, the range of disease incidence within a plot will also impact the power law parameters due to changes in the size of the $x$ space (i.e., the length of the $x$ axis). In other words, the power law parameters from a subset of data with a smaller range of values than the full data set can be significantly different than the parameters from an analysis of the full data set (data not shown). This will be true if the range of incidence falls between 0.2 and 0.8 , where the binomial variability is greatest, or if data do not contain both small $(<0.02)$ and high $(>0.85)$ values of incidence.

The analyses performed here were useful for characterizing the general spatial and temporal trends of shoot blight epidemics and for identifying factors that contributed to the observed disease patterns of fire blight. The results will be useful for designing future studies focused on identifying factors that lead to the observed spatial and temporal differences. However, the parameters estimated from these analyses should not be used in larger scale applications (for example, to design sampling strategies), although the informa- tion could be used as a starting point for designing larger scale surveys. The relatively small plot size and the mixed cultivars simply do not represent the typical orchard scenario. Moreover, the fact that these parameters can change in a single, relatively small location should give an indication of the variability that could exist across the region that this study could not have possibly captured. Finally, the study only took into account disease incidence and not the disease severity of individual trees. Therefore, the contributing influence of the variability of inoculum potential among trees was not taken into account.
In summary, the study showed that the rate of disease spread can be described by a logistic model with apparent infection rates of up to $0.2 /$ day for the susceptible cv. York and 0.16/day for Fuji. Shoot blight epidemics exhibit aggregation that can be described by the $\beta$-binomial distribution, and the degree of aggregation changes systematically with disease incidence and is affected by temporal and location factors.

\section{ACKNOWLEDGMENTS}

This work was supported by the West Virginia Tree Fruit Assessment Board, the State Horticultural Association of Pennsylvania, the Northeast

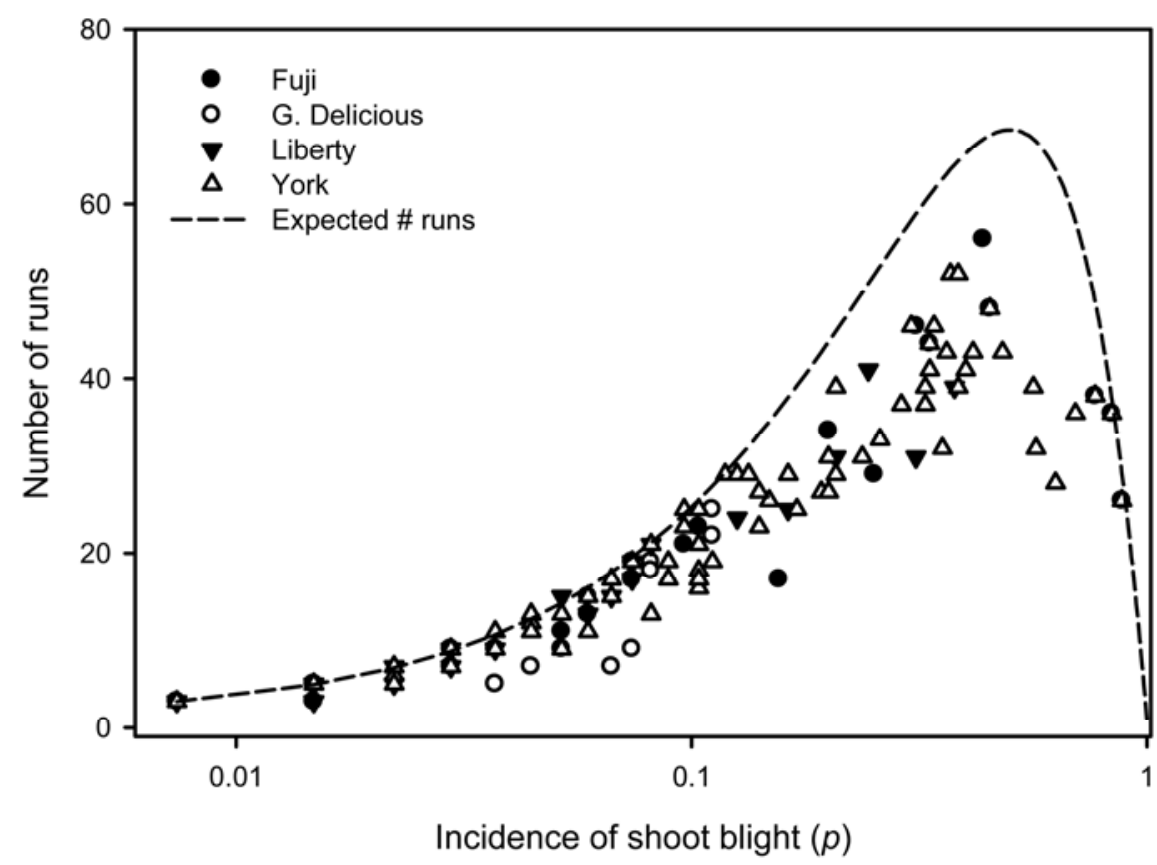

Fig. 3. Relationship between the incidence of shoot blight $(p)$ and the observed number of runs for cvs. Fuji, Golden Delicious, Liberty, and York. The expected number of runs is shown as a broken line and calculated with the equation $1+2 m n / N$, where $N=$ the number of trees (135), $m=$ the number of disease trees, and $n=$ the number of healthy trees.

Table 4. Error sum of squares (SSE) and sequential $F$ tests for the covariance models testing for the effects of the factors 'year,' 'cultivar,' 'plot,' and 'observation date' (Obs) on the intercept and slope parameters of the binary power law for the incidence of shoot blight in experimental orchard plots in Kearneysville, WV from 1994 to $1997^{\text {a }}$

\begin{tabular}{|c|c|c|c|c|c|c|c|c|c|c|}
\hline \multirow[b]{2}{*}{ Data set, model } & \multirow[b]{2}{*}{$\mathbf{d f}_{\mathbf{1}}$} & \multirow[b]{2}{*}{$\mathbf{d f}_{2}$} & \multicolumn{4}{|c|}{ Intercept } & \multicolumn{4}{|c|}{ Slope } \\
\hline & & & SSE & Type I & $\boldsymbol{F}$ & $P$ & SSE & Type I & $\boldsymbol{F}$ & $P$ \\
\hline \multicolumn{11}{|l|}{ Full } \\
\hline Power law & 209 & 13.893 & & & & & $\ldots$ & $\ldots$ & $\ldots$ & $\ldots$ \\
\hline +Year & 206 & 3 & 13.469 & 0.425 & 2.17 & 0.093 & 12.433 & 1.035 & 5.64 & 0.001 \\
\hline+ Cultivar & 206 & 3 & 13.334 & 0.560 & 2.88 & 0.037 & 13.094 & 0.240 & 1.24 & 0.296 \\
\hline +Plot & 204 & 5 & 11.325 & 2.569 & 9.25 & 0.000 & 10.894 & 0.432 & 1.58 & 0.168 \\
\hline$+\mathrm{Obs}$ & 202 & 7 & 13.792 & 0.102 & 0.21 & 0.982 & 13.343 & 0.449 & 0.94 & 0.479 \\
\hline \multicolumn{11}{|l|}{1995} \\
\hline Power law & 123 & 8.731 & & & & & & & & \\
\hline +Cultivar & 120 & 3 & 7.750 & 0.982 & 5.07 & 0.002 & 7.467 & 0.283 & 1.48 & 0.225 \\
\hline +Plot & 118 & 5 & 6.881 & 1.851 & 6.35 & 0.000 & 5.977 & 0.904 & 3.42 & 0.007 \\
\hline$+\mathrm{Obs}$ & 117 & 6 & 8.456 & 0.276 & 0.64 & 0.701 & 8.039 & 0.417 & 0.96 & 0.456 \\
\hline \multicolumn{11}{|l|}{ York } \\
\hline Power law & 123 & 8.863 & & & & & & & & \\
\hline +Year & 120 & 3 & 7.932 & 0.800 & 4.03 & 0.009 & 6.937 & 0.995 & 5.59 & 0.001 \\
\hline+ Plot & 118 & 5 & 6.423 & 2.301 & 8.48 & 0.000 & 5.634 & 0.789 & 3.16 & 0.010 \\
\hline$+\mathrm{Obs}$ & 116 & 7 & 8.698 & 0.034 & 0.06 & 1.000 & 8.369 & 0.328 & 0.61 & 0.746 \\
\hline
\end{tabular}

${ }^{a} \ln \left(A_{\mathrm{x}}\right)$ and $b$ are the intercept and slope parameters, respectively, of the binary power law; $\mathrm{df}_{1}$ is the degrees of freedom for the model; $\mathrm{df}_{2}$ is the degrees of freedom for the factor in test; Type I sum of squares indicates the reduction in SSE as a result of the inclusion of the factor in test; and the $F$ test is a test of a factor's significance based on its sequential sum of squares. 
Region Sustainable Agriculture Research and Education (SARE) Program, and the United States Department of Agriculture National Research Initiative. We thank B. Bergman, J. Wood, and I. Myers for their technical assistance.

\section{LITERATURE CITED}

1. Aldwinckle, H. S. 1974. Field susceptibility of 46 apple cultivars to fire blight. Plant Dis. Rep. 58:819-821.

2. Biggs, A. R. 1999. Analysis of fire blight epidemics with spatio-temporal distance class analysis. (Abstr.) Phytopathology 89:S98.

3. Bogs, J., Bruchmüller, I., Erbar, C., and Geider, K. 1998. Colonization of host plants by the fire blight pathogen Erwinia amylovora marked with genes for bioluminescence and fluorescence. Phytopathology 88:416-421.

4. Bonn, G., and Leuty, T. 1993. As assessment of the Maryblyt computer program for the prediction of fire blight in Ontario, Canada. Acta Hortic. 338:145-152.

5. Clarke, G., Hickey, K., and Travis, J. 1992. Fire blight management: evaluation and role of aphids in transmission of bacteria and development of a computerized management system for growers. Pa. Fruit News 72:30-33.

6. Dewdney, M. M., Biggs, A. R., and Turechek, W. W. 2007. A statistical comparison of the blossom blight forecasts of MARYBLYT and Cougarblight with receiver operating characteristic curve analysis. Phytopathology 97:1164-1176.

7. Gibbons, J. D. 1985. Nonparametric Methods for Quantitative Analysis 2nd ed. American Sciences Press, Inc., Columbus, OH.

8. Jones, A. L. 1992. Evaluation of the computer model Maryblyt for predicting fire blight blos- som infection on apple in Michigan. Plant Dis. 76:344-347.

9. Jones, A. L., and Aldwinckle, H. S. 1990. Compendium of Apple and Pear Diseases. American Phytopathological Society, St. Paul, $\mathrm{MN}$.

10. Madden, L. V. 1980. Quantification of disease progression. Prot. Ecol. 2:159-176.

11. Madden, L. V., and Hughes, G. 1994. BBDcomputer software for fitting the beta-binomial distribution to disease incidence data. Plant Dis. 78:536-540.

12. Madden, L. V., Hughes, G., and van den Bosch, F. 2007. The Study of Plant Disease Epidemics. American Phytopathological Society Press, St. Paul, MN.

13. McManus, P. S., and Jones, A. L. 1994. Role of wind-driven rain, aerosols, and contaminated budwood in incidence and spatial pattern of fire blight in an apple nursery. Plant Dis. 78:1059-1066

14. Norelli, J. L., Jones, A. L., and Aldwinckle, H. S. 2003. Fire blight management in the twentyfirst century: Using new technologies that enhance host resistance in apple. Plant Dis. 87:756-765.

15. Pfeiffer, D. G., Killian, J. C., and Yoder, K. S. 1999. Clarifying the roles of white apple leafhopper and potato leafhopper (Homoptera: Cicadellidae) in fireblight transmission in apple. J. Entomol. Sci. 34:314-321.

16. Steiner, P. W. 1990. Predicting canker, shoot, and trauma blight phases of apple fire blight epidemics using the Maryblyt program. Acta Hortic. 273:149-158.

17. Sutton, T. B., and Pope, L. R. 1989. The susceptibility of scab immune cultivars and selections of apple to fire blight and cedar apple rust. Biol. Cult. Tests 5:4.

18. Thomas, T. M., and Jones, A. L. 1992. Severity of fire blight on apple cultivars and strains in Michigan. Plant Dis. 76:1049-1052.

19. Thomson, S. V. 2000. Epidemiology of Fire Blight, In: Fire Blight, The Disease and its Causative Agent, Erwinia amylovora. J. L. Vanneste, ed. CABI Publishing, New York.

20. Turechek, W. W., and Madden, L. V. 1999. Spatial pattern analysis of strawberry leaf blight in perennial production systems. Phytopathology 89:421-433.

21. Turechek, W. W., and Mahaffee, W. F. 2004 Spatial pattern analysis of hop powdery mildew in the Pacific Northwest: implications for sampling. Phytopathology 94:1116-1128

22. van der Zwet, T., Biggs, A. R., Heflebower, R., and Lightner, G. 1994. Evaluation of the Maryblyt computer model for predicting blossom blight on apple in West Virginia and Maryland. Plant Dis. 78:225-230.

23. van der Zwet, T., and Keil, H. L. 1979. Fire blight - a bacterial disease of Rosaceous plants. U.S. Dep. Agric. Agric. Handb. 510.

24. Williams, D. A. 1975. The analysis of binary responses from toxicological experiments involving reproduction and teratogenicity. Biometrics 31:949-952.

25. Yoder, K. S., Biggs, A. R., and Norelli, J. 2002. Effectiveness of prohexadione-Ca (Apogee 27.5DF) for fire blight shoot blight suppression in commercial apple orchards. (Abstr.) Phytopathology 92:S19.

26. Yoder, K. S., Miller S. S., and Byers, R. E. 1999. Suppression of fireblight in apple shoots by prohexadione-calcium (BAS $125 \mathrm{~W}$ ) following experimental and natural inoculation conditions. HortScience 34:1202-1204. 